\title{
Normal-Coordinate Analysis of Poly(Vinyl Chloride) and Deuterated Analogs
}

\author{
Mitsuo Tasumi and Takehiko Shimanouchi \\ Department of Chemistry, Faculty of Science, University of Tokyo, \\ Bunkyo-ku, Tokyo, Japan.
}

(Received September 2, 1970)

\begin{abstract}
Normal-vibration frequencies of the extended syndiotatic structure of poly(vinyl chloride) and deuterated analogs $\left(\alpha-d_{1}, \beta-d_{1}, \alpha, \beta-d_{2}, \beta, \beta-d_{2}\right.$, and $\left.d_{3}\right)$ were calculated with the modified Urey-Bradley force field. The results were utilized to analyze the infrared spectra of these polymers and detailed assignments were given to most of the crystalline bands.
\end{abstract}

KEY WORDS Infrared Spectrum/Poly(Vinyl Chloride)/Deuterated Analogs/ Normal Coordinate/Vibration Frequency/Force Field/ Assignment/

It is well known that the analysis of the infrared and Raman spectra provide valuable information on the conformation, structural irregularity, crystallinity etc., of various high polymers. The first step of the spectral analysis is always the establishment of the band assignments for regular structures.

Previously we reported a normal-coordinate treatment and assignments of infrared-absorption bands of poly(vinyl chloride) (PVC) and fully deuterated species $\left(\mathrm{PVC}-d_{3}\right)^{1}$. However, the force field used at that time was rather crude, and it was desired to refine the force field, so that more definite assignments of bands could be obtained. Since then, we have studied the molecular vibrations of polyethylene and obtained a reliable set of force constants related to the $\mathrm{CH}_{2}$ group ${ }^{2}$. In order to get the force constants of the $\mathrm{CHCl}$ group, we have calculated the normal frequencies of some small molecules containing the $\mathrm{Cl}$ atom such as $\mathrm{CH}_{3} \mathrm{CH}_{2} \mathrm{Cl}, \quad \mathrm{CH}_{3} \mathrm{CHClCH}_{3}$, and $\left(\mathrm{CH}_{3}\right)_{3} \mathrm{CCl}$.

Experimentally also, there have been several efforts to make the band assignments clearer. Inversion of dichroism was found for some bands with the degree of stretching the film. The interpretation of this fact furnished the basis for the assignments of bands to the symmetry species expected to the extended syndiotactic structure ${ }^{3}$. Highly syndiotactic (therefore highly crystalline) samples of PVC, PVC- $\alpha-d_{1}$, PVC- $\beta-d_{1}$, PVC- $\alpha, \beta-$ $d_{2}$, and PVC- $d_{3}$ were prepared and their spectra were discussed by Krimm, et al. ${ }^{4}$ Later PVC$\beta, \beta-d_{2}$ was also studied by Enomoto, et al. ${ }^{5}$

The Raman spectra of normal and urea-complex PVC were studied by Koenig and Druesedow. ${ }^{6}$ The results are in support of the infrared studies and are utilized in this paper also.

As we shall see below, the calculation by the use of a refined set of force constants provides systematic understanding of the bands of PVC and its deuterated analogs.

\section{NORMAL-COORDINATE TREATMENT}

\section{Structure}

In this study we are interested in the extended syndiotactic structure shown in Figure 1a. Here we assume that the bond angles around a carbon atom are tetrahedral and the bond lengths of $\mathrm{CC}, \mathrm{CH}$, and $\mathrm{CCl}$ bonds are, respectively, 1.54, 1.09 , and $1.77 \AA$. The structure has a glide plane $\left(\sigma_{g}\right)$, a twofold axis $\left(\mathrm{C}_{2}\right)$, and a mirror plane $\left(\sigma_{v}\right)$ which form the $\mathrm{C}_{2 v}$ symmetry. This symmetry remains unaltered in PVC- $\alpha-d_{1}$, PVC- $\beta, \beta-d_{2}$, and PVC- $d_{3}$, whereas PVC- $\beta-d_{1}$ and PVC- $\alpha, \beta-d_{2}$ have lower symmetry because they lose the twofold axis passing through the methylene group. Furthermore, there can be various configurations associated with the $\beta$-deuterium (or hydrogen) atoms in these two polymers. In the present study we assume the disyndiotatic configurations 


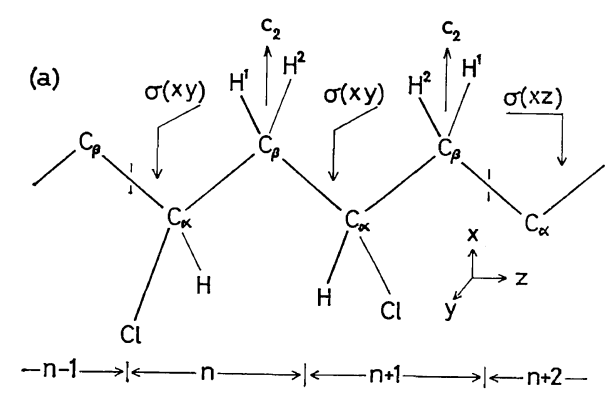

(b)
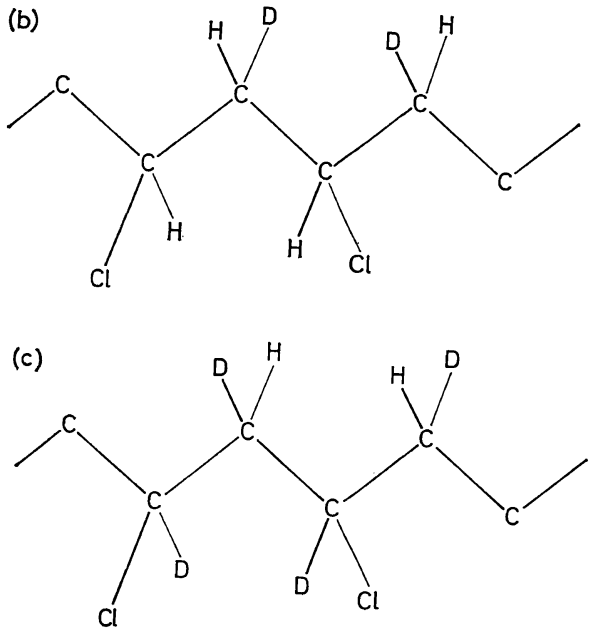

Figure 1. (a) Extended syndiotactic structure of PVC, (b) Disyndiotactic structure of PVC- $\beta-d_{1}$, and (c) Disyndiotactic structure of PVC- $\alpha, \beta-d_{2}$.

Table I. Symmetry properties, number of normal modes, and selection rules of (a) PVC, PVC- $\alpha-d_{1}$, PVC- $\beta, \beta-d_{2}$, and PVC- $d_{3}$ and (b) PVC- $\beta-d_{1}$ and PVC- $\alpha, \beta-d_{2}$

\begin{tabular}{|c|c|c|c|c|c|c|c|c|}
\hline \multirow{5}{*}{ (a) } & $\mathrm{C}_{2 v}$ & $E$ & $C_{2}$ & $\sigma_{g}$ & $\sigma_{v}$ & $n_{i}$ & IR & $\mathbf{R}$ \\
\hline & $A_{1}$ & 1 & 1 & 1 & 1 & 9 & $M_{x}$ & $\mathrm{a}$ \\
\hline & $A_{2}$ & 1 & 1 & -1 & -1 & 7 & $f$ & $\mathrm{a}$ \\
\hline & $B_{1}$ & 1 & -1 & 1 & -1 & 7 & $M_{z}$ & $\mathrm{a}$ \\
\hline & $B_{2}$ & 1 & -1 & -1 & 1 & 9 & $M_{y}$ & $a$ \\
\hline \multirow{3}{*}{ (b) } & $C_{s}$ & \multicolumn{2}{|c|}{$E$} & $\sigma_{g}$ & $n_{i}$ & \multicolumn{2}{|c|}{$I R$} & $R$ \\
\hline & $A^{\prime}$ & \multicolumn{2}{|c|}{1} & 1 & 16 & \multicolumn{2}{|c|}{$M_{x}, M_{z}$} & $\mathrm{a}$ \\
\hline & $A^{\prime \prime}$ & \multicolumn{2}{|c|}{1} & -1 & 16 & \multicolumn{2}{|c|}{$M_{y}$} & $\mathrm{a}$ \\
\hline
\end{tabular}

a $n_{i}$, number of normal modes; IR, infrared; $\mathrm{R}$, Raman; a, active; f, forbidden.

illustrated in Figures $1 \mathrm{~b}$ and 1c, which are the most probable structures expected for the poly- mers obtained by the $\gamma$-radiation polymerization of urea-complexes of pure monomers. The factor-group symmetry of the assumed disyndiotactic structure is $\mathrm{C}_{s}$, since it has only a glide plane. Table I shows the symmetry analysis of the normal vibrations of the $\mathrm{C}_{2 v}$ and $\mathrm{C}_{s}$ structures. The species $A_{1}$ and $B_{1}$ of the $\mathrm{C}_{2 v}$ structure are correlated with the species $A^{\prime}$ of the $\mathrm{C}_{s}$ structure. Similarly $A_{2}$ and $B_{2}$ are correlated with $A^{\prime \prime}$. The transition moments of the $A_{1}$, $B_{2}$, and $A^{\prime \prime}$ vibrations are directed perpendicular to the chain, while those of $B_{1}$ are parallel and those of $A^{\prime}$ are either parallel or perpendicular.

\section{Coordinates}

The internal and local-symmetry coordinates are listed in Tables II and III, respectively.

Table II. Internal coordinates

$$
\begin{aligned}
& \Delta r_{\alpha n}^{\mathrm{Cl}}=\mathrm{C}_{\alpha n}-\mathrm{Cl} \text { stretching } \\
& \Delta r_{\alpha n}^{\mathrm{H}}=\mathrm{C}_{\alpha n}-\mathrm{H} \text { stretching } \\
& \Delta \Theta_{\alpha n}=\mathrm{C}_{\beta n-1}-\mathrm{C}_{\alpha n}-\mathrm{C}_{\beta n} \text { bending } \\
& \Delta \theta_{\alpha n}=\mathrm{H}_{\alpha n}-\mathrm{C}_{\alpha n}-\mathrm{Cl} \text { bending } \\
& \Delta \gamma_{\alpha n}^{1}=\mathrm{C}_{\beta n-1}-\mathrm{C}_{\alpha n}-\mathrm{Cl} \text { bending } \\
& \Delta \gamma_{\alpha n}^{2}=\mathrm{C}_{\beta n-1}-\mathrm{C}_{\alpha n}-\mathrm{H} \text { bending } \\
& \Delta \gamma_{\alpha n}^{3}=\mathrm{C}_{\beta n}-\mathrm{C}_{\alpha n}-\mathrm{Cl} \text { bending } \\
& \Delta \gamma_{\alpha n}^{4}=\mathrm{C}_{\beta n}-\mathrm{C}_{\alpha n}-\mathrm{H} \text { bending } \\
& \Delta \gamma_{n}=\mathrm{C}_{\alpha n}-\mathrm{C}_{\beta n} \text { stretching } \\
& \Delta t_{n}=\text { Internal rotation a around } \mathrm{C}_{\alpha n}-\mathrm{C}_{\beta n} \\
& \Delta r_{\beta n}^{1}=\mathrm{C}_{\beta n}-\mathrm{H}_{n}^{1} \text { stretching } \\
& \Delta r_{\beta n}^{2}=\mathrm{C}_{\beta n}-\mathrm{H}_{n}^{2} \text { stretching } \\
& \Delta \Theta_{\beta n}=\mathbf{C}_{\alpha n}-\mathbf{C}_{\beta n}-\mathbf{C}_{\alpha n+1} \text { bending } \\
& \Delta \theta_{\beta n}=\mathbf{H}_{n}^{1}-\mathbf{C}_{\beta n}-\mathbf{H}_{n}^{2} \text { bending } \\
& \Delta \gamma_{\beta n}^{1}=\mathrm{C}_{\alpha n}-\mathrm{C}_{\beta n}-\mathrm{H}_{n}^{1} \text { bending } \\
& \Delta \gamma_{\beta n}^{2}=\mathrm{C}_{\alpha n}-\mathrm{C}_{\beta n}-\mathrm{H}_{n}^{2} \text { bending } \\
& \Delta \gamma_{\beta n}^{3}=\mathrm{C}_{\alpha n+1}-\mathrm{C}_{\beta n}-\mathrm{H}_{n}^{1} \text { bending } \\
& \Delta \gamma_{\beta n}^{4}=\mathrm{C}_{\alpha n+1}-\mathrm{C}_{\beta n}-\mathrm{H}_{n}^{2} \text { bending } \\
& \Delta r_{n+1 / 2}=\mathrm{C}_{\beta n}-\mathrm{C}_{\alpha n+1} \text { stretching } \\
& \Delta t_{n+1 / 2}=\text { Internal rotation a around } \mathrm{C}_{\beta n}-\mathrm{C}_{\alpha n+1}
\end{aligned}
$$
ref 2 .

Some of the local-symmetry coordinates are different from what were used in the former study. ${ }^{1}$ The coordinates related to the spectroscopically active vibrations (or factor-group vibrations) are given in Table IV. 


\section{Tasumi and T. Shimanouchi}

Table III. Local-symmetry coordinates

\begin{tabular}{|c|c|}
\hline$R_{\alpha n}^{1}=\Delta r_{\alpha n}^{H}$ & $\mathrm{CH}$ stretching \\
\hline$R_{\alpha n}^{2}=\Delta r_{\alpha n}^{\mathrm{Cl}}$ & $\mathrm{CCl}$ stretching \\
\hline$R_{\alpha n}^{3}=\frac{1}{\sqrt{6}}\left(2 \Delta \theta_{\alpha n}-\Delta \gamma_{\alpha n}^{2}-\Delta \gamma_{\alpha n}^{4}\right)$ & $\mathrm{CH}$ bending \\
\hline$R_{\alpha n}^{4}=\frac{1}{\sqrt{6}}\left(\Delta \Theta_{\alpha n}-\Delta \theta_{\alpha n}+\Delta \gamma_{\alpha n}^{1}-\Delta \gamma_{\alpha n}^{2}+\Delta \gamma_{\alpha n}^{3}-\Delta \gamma_{\alpha n}^{4}\right)$ & Deformation 1 \\
\hline$R_{\alpha n}^{5}=\frac{1}{\sqrt{6}}\left(2 \Delta \Theta_{\alpha n}-\Delta \gamma_{\alpha n}^{1}-\Delta \gamma_{\alpha n}^{3}\right)$ & Deformation 2 \\
\hline$R_{\alpha n}^{6}=\frac{1}{\sqrt{2}}\left(\Delta \gamma_{\alpha n}^{2}-\Delta \gamma_{\alpha n}^{4}\right)$ & $\mathrm{CH}$ wagging \\
\hline$R_{\alpha n}^{7}=\frac{1}{\sqrt{2}}\left(\Delta \gamma_{\alpha n}^{1}-\Delta \gamma_{\alpha n}^{3}\right)$ & $\mathrm{CCl}$ wagging \\
\hline$R_{\alpha n}^{8}=\Delta r_{n}$ & CC stretching \\
\hline$R_{\alpha n}^{9}=\Delta t_{n}$ & Internal rotation \\
\hline$R_{\beta n}^{1}=\frac{1}{\sqrt{2}}\left(\Delta r_{\beta n}^{1}+\Delta r_{\beta n}^{2}\right)$ & $\mathrm{CH}_{2}$ symmetric stretching \\
\hline$R_{\beta n}^{2}=\frac{1}{\sqrt{20}}\left(4 \Delta \theta_{\beta n}-\Delta \gamma_{\beta n}^{1}-\Delta \gamma_{\beta n}^{2}-\Delta \gamma_{\beta n}^{3}-\Delta \gamma_{\beta n}^{4}\right)$ & $\mathrm{CH}_{2}$ scissor \\
\hline$R_{\beta n}^{3}=\frac{1}{\sqrt{30}}\left(5 \Delta \Theta_{\beta n}-\Delta \theta_{\beta n}-\Delta \gamma_{\beta n}^{1}-\Delta \gamma_{\beta n}^{2}-\Delta \gamma_{\beta n}^{3}-\Delta \gamma_{\beta n}^{4}\right)$ & $\mathrm{CCC}$ bending \\
\hline$R_{\beta n}^{4}=\frac{1}{2}\left(\Delta \gamma_{\beta n}^{1}-\Delta \gamma_{\beta n}^{2}-\Delta \gamma_{\beta n}^{3}+\Delta \gamma_{\beta n}^{4}\right)$ & $\mathrm{CH}_{2}$ twisting \\
\hline$R_{\beta n}^{5}=\frac{1}{\sqrt{2}}\left(\Delta r_{\beta n}^{1}-\Delta r_{\beta n}^{2}\right)$ & $\mathrm{CH}_{2}$ antisymmetric stretching \\
\hline$R_{\beta n}^{6}=\frac{1}{2}\left(\Delta \gamma_{\beta n}^{1}+\Delta \gamma_{\beta n}^{2}-\Delta \gamma_{\beta n}^{3}-\Delta \gamma_{\beta n}^{4}\right)$ & $\mathrm{CH}_{2}$ wagging \\
\hline$R_{\beta n}^{7}=\frac{1}{2}\left(\Delta \gamma_{\beta n}^{1}-\Delta \gamma_{\beta n}^{2}+\Delta \gamma_{\beta n}^{3}-\Delta \gamma_{\beta n}^{4}\right)$ & $\mathrm{CH}_{2}$ rocking \\
\hline$R_{\beta n}^{8}=\Delta r_{n+1 / 2}$ & CC stretching \\
\hline$R_{\beta n}^{9}=\Delta t_{n+1 / 2}$ & Internal rotation \\
\hline
\end{tabular}

Table IV. Spectroscopically active coordinates

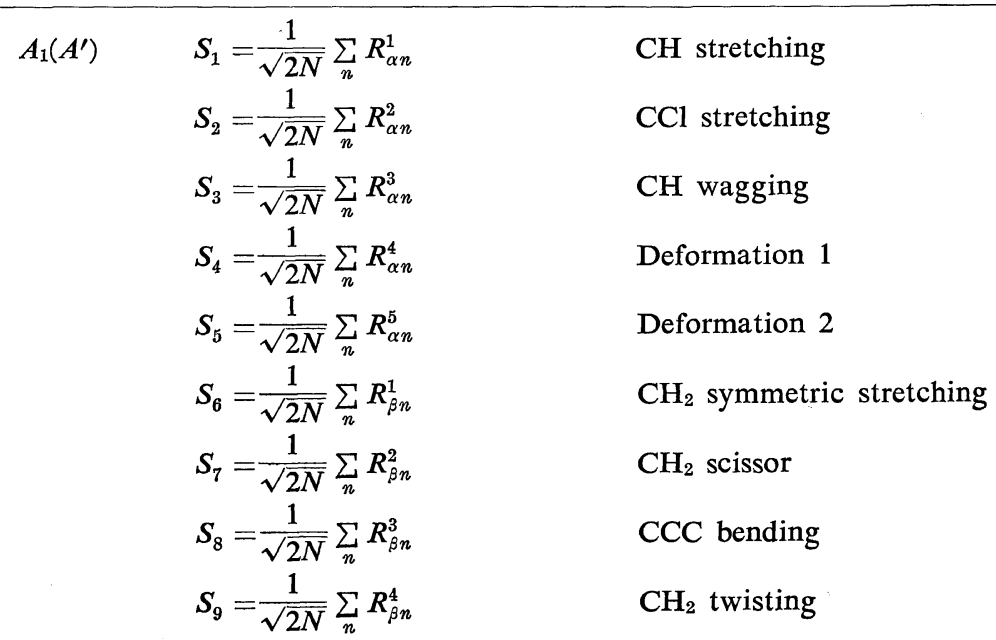


Normal-Coordinate Analysis of Poly(Vinyl Chloride) and Deuterated Analogs

Table IV. (continued)

$$
\begin{aligned}
& S_{10}=\frac{1}{\sqrt{4 N}} \sum_{n}\left(R_{\alpha n}^{8}+R_{\beta n}^{8}\right) \quad \text { CC stretching } \\
& S_{11}=\frac{1}{\sqrt{4 N}} \sum_{n}(-1)^{n}\left(R_{\alpha n}^{9}+R_{\beta n}^{9}\right) \quad \text { Internal rotation } \\
& A_{2}\left(A^{\prime \prime}\right) \quad S_{12}=\frac{1}{\sqrt{2 N}} \sum_{n}(-1)^{n} R_{\alpha n}^{6} \quad \text { CH wagging } \\
& S_{13}=\frac{1}{\sqrt{2 N}} \sum_{n}(-1)^{n} R_{\alpha n}^{7} \quad \text { CCl wagging } \\
& S_{14}=\frac{1}{\sqrt{2 N}} \sum_{n}(-1)^{n} R_{\beta n}^{1} \quad \mathrm{CH}_{2} \text { symmetric stretching } \\
& S_{15}=\frac{1}{\sqrt{2 N}} \sum_{n}(-1)^{n} R_{\beta n}^{2} \quad \mathrm{CH}_{2} \text { scissor } \\
& S_{16}=\frac{1}{\sqrt{2 N}} \sum_{n}(-1)^{n} R_{\beta n}^{3} \quad \text { CCC bending } \\
& S_{17}=\frac{1}{\sqrt{2 N}} \sum_{n}(-1)^{n} R_{\beta n}^{4} \quad \mathrm{CH}_{2} \text { twisting } \\
& S_{18}=\frac{1}{\sqrt{4 N}} \sum_{n}(-1)^{n}\left(R_{\alpha n}^{8}+R_{\beta n}^{8}\right) \quad \text { CC stretching } \\
& S_{19}=\frac{1}{\sqrt{4 N}} \sum_{n}\left(R_{\alpha n}^{9}+R_{\beta n}^{9}\right) \quad \text { Internal rotation } \\
& B_{1}\left(A^{\prime}\right) \quad S_{20}=\frac{1}{\sqrt{2 N}} \sum_{n} R_{\alpha n}^{6} \quad \text { CH wagging } \\
& S_{21}=\frac{1}{\sqrt{2 N}} \sum_{n} R_{\alpha n}^{7} \quad \mathrm{CCl} \text { wagging } \\
& S_{22}=\frac{1}{\sqrt{2 N}} \sum_{n} R_{\beta n}^{5} \quad \mathrm{CH}_{2} \text { antisymmetric stretching } \\
& S_{23}=\frac{1}{\sqrt{2 N}} \sum_{n} R_{\beta n}^{6} \quad \mathrm{CH}_{2} \text { wagging } \\
& S_{24}=\frac{1}{\sqrt{2 N}} \sum_{n} R_{\beta n}^{7} \quad \mathrm{CH}_{2} \text { rocking } \\
& S_{25}=\frac{1}{\sqrt{4 N}} \sum_{n}\left(R_{\alpha n}^{8}-R_{\beta n}^{8}\right) \quad \text { CC stretching } \\
& S_{26}=\frac{1}{\sqrt{4 N}} \sum_{n}(-1)^{n}\left(R_{\alpha n}^{9}-R_{\beta n}^{9}\right) \quad \text { Internal rotation } \\
& B_{2}\left(A^{\prime \prime}\right) \quad S_{27}=\frac{1}{\sqrt{2 N}} \sum_{n}(-1)^{n} R_{\alpha n}^{1} \quad \text { CH stretching } \\
& S_{28}=\frac{1}{\sqrt{2 N}} \sum_{n}(-1)^{n} R_{\alpha n}^{2} \quad \text { CCl stretching } \\
& S_{29}=\frac{1}{\sqrt{2 N}} \sum_{n}(-1)^{n} R_{\alpha n}^{3} \quad \text { CH bending } \\
& S_{30}=\frac{1}{\sqrt{2 N}} \sum_{n}(-1)^{n} R_{\alpha n}^{4} \quad \text { Deformation } 1 \\
& S_{31}=\frac{1}{\sqrt{2 N}} \sum_{n}(-1)^{n} R_{\alpha n}^{5} \quad \text { Deformation 2 } \\
& S_{32}=\frac{1}{\sqrt{2 N}} \sum_{n}(=1)^{n} R_{\beta n}^{5} \quad \quad \mathrm{CH}_{2} \text { antisymmetric stretching } \\
& S_{33}=\frac{1}{\sqrt{2 N}} \sum_{n}(-1)^{n} R_{\beta n}^{6} \quad \mathrm{CH}_{2} \text { wagging } \\
& S_{34}=\frac{1}{\sqrt{2 N}} \sum_{n}(-1)^{n} R_{\beta n}^{7} \quad \mathrm{CH}_{2} \text { rocking } \\
& S_{35}=\frac{1}{\sqrt{4 N}} \sum_{n}(-1)^{n}\left(R_{\alpha n}^{8}-R_{\beta n}^{8}\right) \quad \text { CC stretching } \\
& S_{36}=\frac{1}{\sqrt{4 N}} \sum_{n}\left(R_{\alpha n}^{9}-R_{\beta n}^{9}\right) \quad \text { Internal rotation }
\end{aligned}
$$




\section{TASUmi and T. Shimanouchi}

\section{Force Constants}

We used a modified Urey-Bradley force field which is given in Table V. Besides the conventional Urey-Bradley force constants represented by $K, H, F$, and $\kappa^{7}$, some valence force constants are included. The constant $p(\mathrm{CC}, \mathrm{CC})$ represents the interaction term between the

Table V. Force constants ${ }^{a}$

\begin{tabular}{|c|c|c|c|}
\hline \multicolumn{4}{|c|}{ Urey-Bradly force constants ${ }^{a}$} \\
\hline$K(\mathrm{C}-\mathrm{C})$ & 2.541 & $H(\mathrm{Cl}-\mathrm{C}-\mathrm{C})$ & 0.130 \\
\hline$K(\mathrm{C}-\mathrm{H})$ of $\mathrm{CH}_{2}$ & 4.122 & $F(\mathrm{C} \ldots \mathrm{C})$ & 0.300 \\
\hline$K(\mathrm{C}-\mathrm{H})$ of $\mathrm{CHCl}$ & 4.072 & $F(\mathbf{H} \ldots \mathrm{H})$ & 0.215 \\
\hline$K(\mathrm{C}-\mathrm{Cl})$ & 1.450 & $F(\mathrm{H} \ldots \mathrm{C})$ & 0.475 \\
\hline$H(\mathrm{C}-$ & 0.2 & $F(\mathrm{H} \ldots \mathrm{Cl})$ & 0.720 \\
\hline$H(\mathrm{l}$ & 0.3 & $F(\mathrm{Cl} \ldots \mathrm{C})$ & 0.600 \\
\hline$H(\mathrm{H}$ & 0.219 & $\kappa$ of $\mathrm{CH}_{2}$ & -0.011 \\
\hline$H(\mathrm{H}-\mathrm{C}-\mathrm{Cl})$ & 0.055 & $\kappa$ of $\mathrm{CHCl}$ & 0.07 \\
\hline \multicolumn{4}{|c|}{ Non-Urey-Bradley force constants } \\
\hline$Y$ & 0.110 & $g^{\prime}$ & -0.005 \\
\hline$p(\mathrm{CH}, \mathrm{CI}$ & -0.116 & $f(\operatorname{sci}$ & 0.007 \\
\hline$p(\mathrm{CC}, \mathrm{CC})$ & -0.078 & $f$ (wag) & -0.013 \\
\hline$t$ & 0.096 & $f$ (ro & 0.013 \\
\hline$g$ & -0.036 & 16 & -0 \\
\hline$i$ & -0.011 & & \\
\hline
\end{tabular}

a Units are $\mathrm{md} / \AA$ for $K, H, F$, and $p$ and $\mathrm{md}$. $\AA$ for $\kappa, Y, t, g, t^{\prime}, g^{\prime}$, and $f$.

b As for the definitions of $Y, p, t, g^{\prime}$, see the text and Figure 2. The constant represented by $f$ is the correction term which should be added to the respective diagonal element of local-symmetry force field. (a)
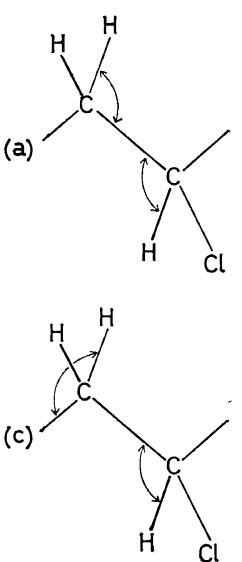

(b)

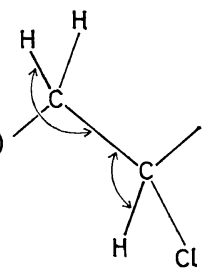

(d)

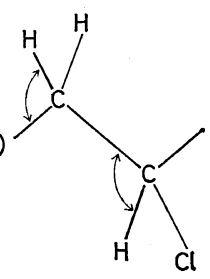

Figure 2. The force constants represented by $t, g$, $t^{\prime}$ and $g^{\prime}$ correspond, respectively, to the interactions between the angles shown in (a), (b), (c), and (d). stretching of two adjacent $\mathrm{CC}$ bonds. Likewise $p(\mathrm{CH}, \mathrm{CH})$ is put between the two $\mathrm{CH}$-stretching coordinates. The definition of $t, t^{\prime}, g$, and $g^{\prime}$ is given in Figure 2. Numerical values of force constants were adjusted by the method of trial and error in order to get a good agreement between the observed and calculated freqaencies. In doing this, great deviations of the values from those of $\mathrm{CH}_{3} \mathrm{CH}_{2} \mathrm{Cl}, \quad \mathrm{CH}_{3} \mathrm{CHClCH}_{3}$, and $\left(\mathrm{CH}_{3}\right)_{3} \mathrm{CCl}$ were avoided to keep the transferability of force constants among similar molecules. The force constants related to the methylene group may be transformed into the local-symmetry force constants given in ref 2 . The internal-rotation constant $Y$ used here for PVC is slightly different from that of polyethylene.

\section{RESULTS AND DISCUSSION}

The results of calculation and our assignments of observed frequencies are shown in Tables VI -XI. Most of the crystalline bands reported in ref 4 could be assigned. Some very weak crystalline bands and amorphous ones were left unassigned.

\section{$P V C$}

The study of dichroism for the films with various draw-ratios has established the symmetry assignments of most of the crystalline bands.

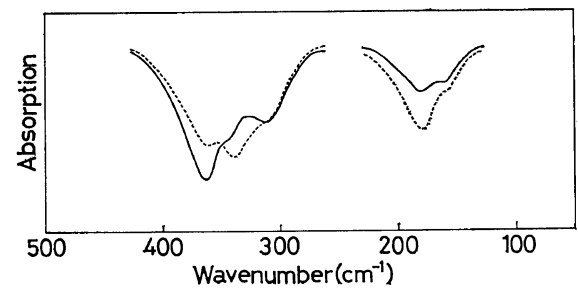

Figure 3. Far-infrared spectra of PVC. The solid and broken curves indicate perpendicular and parallel absorptions, respectively.

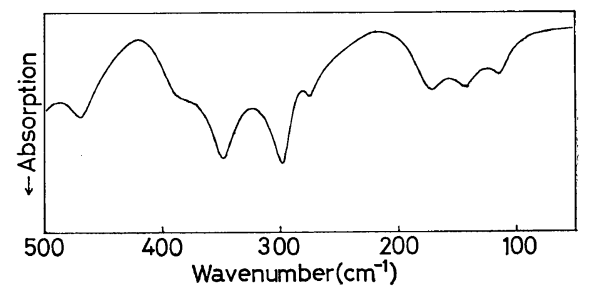

Figure 4. Far-infrared spectrum of PVC- $\beta, \beta-d_{2}$. 
The $A_{1}$ bands are always polarized perpendicularly to the drawing direction, and the $B_{1}$ bands are parallel at high draw-ratios, whereas the dichroism of the $B_{2}$ bands changes from parallel to perpendicular with the degree of drawing. However, there are a few bands which do not exhibit definite dichroic behavior because of the overlapping of other bands or of their very weak intensities. For instance, the band at $1090 \mathrm{~cm}^{-1}$ shows neither clear parallel dichroism at high draw-ratios nor the change of dichroism from parallel to perpendicular. This band is a shoulder of the $1105 \mathrm{~cm}^{-1}$ band which is an $A_{1}$ band. Probably there is also some contribution from the amorphous part in this frequency region. The band at about $1030 \mathrm{~cm}^{-1}$ is very weak and the dichroism is not determined. Having such difficulties in assigning these two bands experimentally to proper symmetry species, we resort to the results of calculation and assign the 1090-

Table VI. Observed and calculated frequencies (in $\mathrm{cm}^{-1}$ ), potential energy distributions, and band assignments of PVC

\begin{tabular}{|c|c|c|c|c|c|c|}
\hline \multicolumn{2}{|c|}{ Mode } & \multicolumn{2}{|c|}{$\begin{array}{c}\text { Obsd frequency } \\
\text { Intensity } \\
\text { Dichroism }^{\mathrm{a}}\end{array}$} & \multirow{2}{*}{$\begin{array}{c}\begin{array}{c}\text { Calcd } \\
\text { frequency }\end{array} \\
2960\end{array}$} & \multirow[t]{2}{*}{$\mathrm{PED}^{\mathrm{b}}$} & \multirow{2}{*}{$\begin{array}{l}\text { Assignment } \\
\mathrm{CH} \text { str. }\end{array}$} \\
\hline$A_{1}$ & $\nu_{1}$ & $2970 \mathrm{mw}$ & $\perp$ & & & \\
\hline & $\nu_{2}$ & $2910 \mathrm{~s}$ & $\perp$ & 2893 & $+S_{6}$ & $\mathrm{CH}_{2}$ sym. str. \\
\hline & $\nu_{3}$ & $1428 \mathrm{~s}$ & $\perp$ & 1445 & $+S_{7}(100)$ & $\mathrm{CH}_{2}$ scis. \\
\hline & $\nu_{4}$ & $1338 \mathrm{~ms}$ & $\perp$ & 1322 & $-S_{9}(47)+S_{3}(45)$ & $\mathrm{CH}_{2}$ twist., $\mathrm{CH}$ bend. \\
\hline & $\nu_{5}$ & & & 1169 & $-S_{3}(46)-S_{9}(39)-S_{10}(16)$ & $\mathrm{CH}$ bend., $\mathrm{CH}_{2}$ twist. \\
\hline & $\nu_{6}$ & $1105 \mathrm{~m}$ & $\perp$ & 1122 & $-S_{10}(46)+S_{8}(18)+S_{5}(16)$ & Skeletatl \\
\hline & $\nu_{7}$ & $640 \mathrm{~s}$ & $\perp$ & 639 & $+S_{2}(95)+S_{4}(24)$ & $\mathrm{CCl}$ str. \\
\hline & $\nu_{8}$ & $364 \mathrm{~m}$ & $\perp$ & 349 & $+S_{4}(57)-S_{2}(16)+S_{5}(15)$ & $\mathrm{CCl}$ bend. \\
\hline & $\nu_{9}$ & & & 54 & $+S_{11}(95)$ & Torsion \\
\hline \multirow[t]{7}{*}{$A_{2}$} & $\nu_{10}$ & & & 2896 & $+S_{14}(101)$ & $\mathrm{CH}_{2}$ sym. str. \\
\hline & $\nu_{11}$ & & & 1440 & $+S_{15}(101)$ & $\mathrm{CH}_{2}$ scis. \\
\hline & $\nu_{12}$ & & & 1351 & $+S_{12}(73)-S_{17}(15)$ & $\mathrm{CH}$ wag. \\
\hline & $\nu_{13}$ & & & 1133 & $+S_{17}(85)+S_{12}(25)$ & $\mathrm{CH}_{2}$ twist. \\
\hline & $\nu_{14}$ & & & 1025 & $+S_{18}(99)$ & CC str. \\
\hline & $\nu_{15}$ & & & 549 & $+S_{16}(65)+S_{13}(30)$ & CCC bend. \\
\hline & $\nu_{16}$ & & & 127 & $+S_{13}(67)-S_{16}(34)$ & $\mathrm{CCl}$ wag. \\
\hline \multirow[t]{7}{*}{$B_{1}$} & $\nu_{17}$ & & & 2949 & $-S_{22}(101)$ & $\mathrm{CH}_{2}$ antisym. str. \\
\hline & $\nu_{18}$ & $1387 \mathrm{w}$ & $/ /$ & 1404 & $+S_{20}(57)-S_{23}(31)+S_{25}(27)$ & $\mathrm{CH}$ wag. \\
\hline & $\nu_{19}$ & $1230 \mathrm{mw}$ & $/ /$ & 1233 & $+S_{23}(70)+S_{20}(34)$ & $\mathrm{CH}_{2}$ wag. \\
\hline & $\nu_{20}$ & $1090 \mathrm{sh}$ & & 1076 & $+S_{25}(78)$ & CC str. \\
\hline & $\nu_{21}$ & $835 \mathrm{mw}$ & $/ /$ & 835 & $-S_{24}(89)$ & $\mathrm{CH}_{2}$ rock. \\
\hline & $\nu_{22}$ & $340 \mathrm{sh}$ & $/ /$ & 347 & $+S_{21}(79)+S_{26}(15)$ & $\mathrm{CCl}$ wag. \\
\hline & $\nu_{23}$ & & & 117 & $-S_{26}(81)$ & Torsion \\
\hline \multirow[t]{9}{*}{$B_{2}$} & $\nu_{24}$ & $2970 \mathrm{mw}$ & $\perp$ & 2962 & $-S_{27}(70)+S_{32}(31)$ & $\mathrm{CH}$ str. \\
\hline & $\nu_{25}$ & $2930 \mathrm{w}$ & $\perp$ & 2944 & $-S_{32}(70)-S_{27}(32)$ & $\mathrm{CH}_{2}$ antisym. str. \\
\hline & $\nu_{26}$ & $1355 \mathrm{w}$ & $\perp$ & 1311 & $+S_{33}(99)$ & $\mathrm{CH}_{2}$ wag. \\
\hline & $\nu_{27}$ & $1258 \mathrm{~s}$ & $\perp$ & 1278 & $+S_{29}(87)$ & $\mathrm{CH}$ bend. \\
\hline & $\nu_{28}$ & $1030 \mathrm{vw}$ & $\perp$ & 1022 & $-S_{35}(78)-S_{34}(20)$ & CC str. \\
\hline & $\nu_{29}$ & $960 \mathrm{~ms}$ & $\perp$ & 1002 & $+S_{34}(44)-S_{35}(28)$ & $\mathrm{CH}_{2}$ rock. \\
\hline & $\nu_{30}$ & $604 \mathrm{~s}$ & $\perp$ & 619 & $-S_{28}(92)-S_{31}(24)$ & $\mathrm{CCl}$ str. \\
\hline & $\nu_{31}$ & $490 \mathrm{w}$ & & 476 & $+S_{30}(76)$ & Deform. 1 \\
\hline & $\nu_{32}$ & $312 \mathrm{w}$ & $\perp$ & 310 & $-S_{31}(63)$ & Deform. 2 \\
\hline
\end{tabular}

a Observed data are taken from ref 3 and 4, and Figure 3.

b Potential-energy distribution (PED) is indicated by the number in parenthesis following symmetry coordinate. The values of PED given here are not normalized to 100 . The sign of corresponding element of eigenvector is also shown. 


\section{Tasumi and T. Shimanouchi}

and $1030-\mathrm{cm}^{-1}$ bands to $\nu_{20}$ (CC-stretching mode of $\left.B_{1}, \nu_{\text {calc }}=1076 \mathrm{~cm}^{-1}\right)$ and $\nu_{28}(C C$-stretching mode of $B_{2}, \nu_{\text {calc }}=1022 \mathrm{~cm}^{-1}$ ), respectively. The $1105-\mathrm{cm}^{-1}$ band is undoubtedly the skeletal mode of $A_{1}\left(\nu_{6}, \nu_{\text {calc }}=1122 \mathrm{~cm}^{-1}\right)$. Such assignments have some analogy to the skeletal modes of polyethylene. In the case of polyethylene ${ }^{2} \nu_{4}(0)$ ( $A_{1}$-type mode), $\nu_{4}(\pi / 2)$ ( $B_{2}$-type mode), $\nu_{4}(\pi)\left(B_{1}-\right.$ type mode) are located, respectively, at $1131 \mathrm{~cm}^{-1}$ about $1000 \mathrm{~cm}^{-1}$, and $1061 \mathrm{~cm}^{-1}$. The mode $\nu_{4}$ $(\pi / 2)$ of polyethylene, which is degenerate, splits into $\nu_{14}\left(A_{2}, \nu_{\text {calc }}=1025 \mathrm{~cm}^{-1}\right)$ and $\nu_{28}\left(B_{2}, \nu_{\text {calc }}=\right.$
$1022 \mathrm{~cm}^{-1}$ ) in the case of PVC. Formerly a parallel band at $1122 \mathrm{~cm}^{-1}$ was assigned to $\nu_{20}$ $\left(B_{1} \text { CC-stretching mode }\right)^{1}$. However, the intensity of this band decreases in the spectrum of the urea-complex PVC and, therefore, this band is associated with the amorphous part ${ }^{4}$. The assignment of the $1195-\mathrm{cm}^{-1}$ band to $\nu_{20}{ }^{4}$ does not seem to have a strong basis to support it.

The assignment of the $1338-\mathrm{cm}^{-1}$ band has been a subject of some discussions ${ }^{3}$. Our present calculation indicates that this band should be assigned to $\nu_{4}$, in which the $\mathrm{CH}_{2}$-twisting and

Table VII. Observed and calculated frequencies (in $\mathrm{cm}^{-1}$ ), potential energy distributions, and band assignments of PVC- $\alpha-d_{1}$

\begin{tabular}{|c|c|c|c|c|c|c|}
\hline \multicolumn{2}{|c|}{ Mode } & \multicolumn{2}{|c|}{$\begin{array}{c}\text { Obsd frequency } \\
\text { Intensity } \\
\text { Dichroism }^{\mathrm{a}}\end{array}$} & \multirow{2}{*}{$\begin{array}{l}\begin{array}{c}\text { Calcd } \\
\text { frequency }\end{array} \\
2897\end{array}$} & PED & \multirow{2}{*}{$\begin{array}{c}\text { Assignment } \\
\mathrm{CH}_{2} \text { sym. str. }\end{array}$} \\
\hline$A_{1}$ & $\nu_{1}$ & $2910 \mathrm{~s}$ & $\perp$ & & $-S_{6}(101)$ & \\
\hline & $\nu_{2}$ & $2200 \mathrm{w}$ & $\perp$ & 2160 & $-S_{1}(102)$ & CD str. \\
\hline & $\nu_{3}$ & $1430 \mathrm{~s}$ & $\perp$ & 1444 & $-S_{7}(101)$ & $\mathrm{CH}_{2}$ scis. \\
\hline & $\nu_{4}$ & $1297 \mathrm{~ms}$ & $\perp$ & 1262 & $+S_{9}(86)$ & $\mathrm{CH}_{2}$ twist. \\
\hline & $\nu_{5}$ & $1110 \mathrm{vw}$ & & 1133 & $+S_{10}(62)-S_{8}(24)-S_{5}(20)$ & Skeletal \\
\hline & $\nu_{6}$ & $888 \mathrm{mw}$ & $\perp$ & 872 & $-S_{3}(97)$ & CD bend. \\
\hline & $\nu_{7}$ & $625 \mathrm{~s}$ & $\perp$ & 630 & $-S_{2}(94)-S_{4}(22)$ & $\mathrm{CCl}$ str. \\
\hline & $\nu_{8}$ & 358 & $\perp$ & 344 & $-S_{4}(58)-S_{5}(15)+S_{2}(15)$ & $\mathrm{CCl}$ bend. \\
\hline & $\nu_{9}$ & & & 54 & $-S_{11}(95)$ & Torsion \\
\hline \multirow{7}{*}{$A_{2}$} & $\nu_{10}$ & & & 2896 & $+S_{14}(101)$ & $\mathrm{CH}_{2}$ sym. str. \\
\hline & $\nu_{11}$ & & & 1440 & $+S_{15}(101)$ & $\mathrm{CH}_{2}$ scis. \\
\hline & $\nu_{12}$ & & & 1210 & $-S_{17}(75)$ & $\mathrm{CH}_{2}$ twist. \\
\hline & $\nu_{13}$ & & & 1073 & $+S_{18}(73)+S_{12}(28)+S_{17}(19)$ & CC str. \\
\hline & $\nu_{14}$ & & & 913 & $+S_{12}(51)-S_{18}(29)$ & CD wag. \\
\hline & $\nu_{15}$ & & & 514 & $-S_{16}(60)-S_{13}(29)+S_{12}(15)$ & CCC bend. \\
\hline & $\nu_{16}$ & & & 127 & $-S_{13}(67)+S_{16}(34)$ & $\mathrm{CCl}$ wag. \\
\hline \multirow[t]{7}{*}{$B_{1}$} & $\nu_{17}$ & & & 2949 & $+S_{22}(101)$ & $\mathrm{CH}_{2}$ antisym. str. \\
\hline & $\nu_{18}$ & $1353 \mathrm{~ms}$ & $1 /$ & 1331 & $+S_{23}(78)-S_{25}(48)$ & $\mathrm{CH}_{2}$ wag. \\
\hline & $\nu_{19}$ & $1160 \mathrm{vw}$ & & 1126 & $-S_{25}(39)-S_{23}(29)-S_{20}(26)$ & CC str. \\
\hline & $\nu_{20}$ & $1000 \mathrm{vw}$ & $1 /$ & 989 & $-S_{24}(35)-S_{25}(25)+S_{20}(23)$ & $\mathrm{CH}_{2}$ rock. \\
\hline & $\nu_{21}$ & $769 \mathrm{~m}$ & /I & 765 & $-S_{24}(57)-S_{20}(45)$ & $\mathrm{CH}_{2}$ rock, $\mathrm{CD}$ wag. \\
\hline & $\nu_{22}$ & 345 & /l & 347 & $-S_{21}(79)-S_{26}(15)$ & $\mathrm{CCl}$ wag. \\
\hline & $\nu_{23}$ & & & 115 & $-S_{26}(81)$ & Torsion \\
\hline \multirow[t]{9}{*}{$B_{2}$} & $\nu_{24}$ & $2935 \mathrm{mw}$ & & 2950 & $-S_{32}(101)$ & $\mathrm{CH}_{2}$ antisym. str. \\
\hline & $\nu_{25}$ & $2200 \mathrm{w}$ & $\perp$ & 2160 & $-S_{27}(103)$ & CD str. \\
\hline & $\nu_{26}$ & $1360 \mathrm{~ms}$ & $\perp$ & 1308 & $+S_{33}(101)$ & $\mathrm{CH}_{2}$ wag. \\
\hline & $\nu_{27}$ & $1080 \mathrm{~s}$ & $\perp$ & 1100 & $+S_{34}(46)-S_{29}(32)$ & $\mathrm{CH}_{2}$ rock., $\mathrm{CD}$ bend. \\
\hline & $\nu_{28}$ & $1020 \mathrm{vw}$ & $\perp$ & 1015 & $+S_{35}(95)$ & CC str. \\
\hline & $\nu_{29}$ & $835 \mathrm{w}$ & $\perp$ & 846 & $-S_{29}(67)-S_{34}(19)$ & CD bend. \\
\hline & $\nu_{30}$ & $598 \mathrm{~s}$ & $\perp$ & 614 & $-S_{28}(94)-S_{31}(22)$ & $\mathrm{CCl}$ str. \\
\hline & $\nu_{31}$ & 473 & & 469 & $+S_{30}(77)$ & Deform. 1 \\
\hline & $\nu_{32}$ & 297 & $\perp$ & 305 & $-S_{31}(64)$ & Deform. 2 \\
\hline
\end{tabular}

a Observed data are taken from ref 4 and 8 . 
CH-bending coordinates are mixed almost equally. Though the amount of mixing may vary depending on the assumed force field, it is certain that they are mixed in $\nu_{4}$.

The calculated frequency of $\nu_{26}\left(\mathrm{CH}_{2}\right.$-wagging mode of $B_{2}$ ) is lower than the observed by about $40 \mathrm{~cm}^{-1}$, whereas the agreement between the observed and calculated frequencies is much better for $\nu_{18}$ and $\nu_{19}$ (CH- and $\mathrm{CH}_{2}$-wagging modes of $B_{1}$ ). This suggests that the force field used here is still capable of some improvement.

Assignments of low-frequency vibrations are also important. In Figure 3 the far-infrared spectrum of a highly sydiotactic sample is shown. The bands at 364,340 , and $312 \mathrm{~cm}^{-1}$ may be assigned, respectively, to $\nu_{8}\left(\mathrm{CCl}\right.$ bending of $\left.A_{1}\right)$, $\nu_{22}\left(\mathrm{CCl}\right.$ bending of $\left.B_{1}\right)$, and $\nu_{32}(\mathrm{CCl}$ bending of $B_{2}$ ) in accordance with the results of calculation and dichroism measurements. We have tentatively taken the $490-\mathrm{cm}^{-1}$ band to $\nu_{31}$ (skeletal-deformation vibration of $B_{2}$ ), though there remains some doubt about its polarization. The parallel band at $180 \mathrm{~cm}^{-1}$ raises a question. From the single-chain analysis, only $\nu_{23}$ (internal rota-

Table VIII. Observed and calculated frequencies (in $\mathrm{cm}^{-1}$ ), potential energy distributions, and band assignments of PVC- $\beta, \beta-d_{2}$

\begin{tabular}{|c|c|c|c|c|c|c|}
\hline \multicolumn{2}{|c|}{ Mode } & \multicolumn{2}{|c|}{$\begin{array}{l}\text { Obsd frequency } \\
\text { Intensity } \\
\text { Dichroism }\end{array}$} & \multirow{2}{*}{$\begin{array}{c}\begin{array}{c}\text { Calcd } \\
\text { frequency }\end{array} \\
2956\end{array}$} & \multirow[b]{2}{*}{$+S_{1}(102)$} & \multirow{2}{*}{$\begin{array}{l}\text { Assignment } \\
\mathrm{CH} \text { str. }\end{array}$} \\
\hline$A_{1}$ & $\nu_{1}$ & $2962 \mathrm{w}$ & $\perp$ & & & \\
\hline & $\nu_{2}$ & $2112 \mathrm{w}$ & $\perp$ & 2099 & $-S_{6}(101)$ & $\mathrm{CD}_{2}$ sym. str. \\
\hline & $\nu_{3}$ & 1252 vs & $\perp$ & 1255 & $+S_{3}(96)$ & $\mathrm{CH}$ bend. \\
\hline & $\nu_{4}$ & $1105 \mathrm{~m}$ & $\perp$ & 1146 & $+S_{10}(51)+S_{7}(27)-S_{5}(16)$ & Skeletal \\
\hline & $\nu_{5}$ & $1020 \mathrm{w}$ & $\perp$ & 1020 & $-S_{7}(73)$ & $\mathrm{CD}_{2}$ scis. \\
\hline & $\nu_{6}$ & $955 \mathrm{w}$ & $\perp$ & 943 & $+S_{9}(75)$ & $\mathrm{CD}_{2}$ twist. \\
\hline & $\nu_{7}$ & $599 \mathrm{~s}$ & $\perp$ & 592 & $-S_{2}(85)+S_{9}(19)-S_{4}(17)$ & $\mathrm{CCl}$ str. \\
\hline & $\nu_{8}$ & $348 \mathrm{~m}$ & & 340 & $-S_{4}(57)-S_{5}(16)$ & $\mathrm{CCl}$ bend. \\
\hline & $\nu_{9}$ & & & 54 & $+S_{11}(95)$ & Torsion \\
\hline \multirow[t]{7}{*}{$A_{2}$} & $\nu_{10}$ & & & 2098 & $+S_{14}(101)$ & $\mathrm{CD}_{2}$ sym. str. \\
\hline & $\nu_{11}$ & & & 1318 & $-S_{12}(93)$ & CH wag. \\
\hline & $\nu_{12}$ & & & 1099 & $+S_{15}(66)+S_{18}(49)$ & $\mathrm{CD}_{2}$ scis., $\mathrm{CC}$ str. \\
\hline & $\nu_{13}$ & & & 969 & $+S_{18}(54)-S_{15}(33)$ & $\mathrm{CC}$ str., $\mathrm{CD}_{2}$ scis. \\
\hline & $\nu_{14}$ & & & 821 & $+S_{17}(99)$ & $\mathrm{CD}_{2}$ twist. \\
\hline & $\nu_{15}$ & & & 527 & $+S_{16}(63)+S_{13}(29)$ & CCC bend. \\
\hline & $\nu_{16}$ & & & 127 & $+S_{13}(67)-S_{16}(34)$ & $\mathrm{CCl}$ wag. \\
\hline \multirow[t]{7}{*}{$B_{1}$} & $\nu_{17}$ & & & 2185 & $-S_{22}(101)$ & $\mathrm{CD}_{2}$ antisym. str. \\
\hline & $\nu_{18}$ & $1325 \mathrm{w}$ & $/ /$ & 1365 & $-S_{20}(77)-S_{25}(30)$ & $\mathrm{CH}$ wag. \\
\hline & $\nu_{19}$ & $1167 \mathrm{~m}$ & $/ /$ & 1140 & $+S_{25}(67)-S_{23}(30)-S_{20}(18)$ & CC str. \\
\hline & $\nu_{20}$ & $885 \mathrm{sh}$ & $1 /$ & 869 & $-S_{23}(69)-S_{25}(15)$ & $\mathrm{CD}_{2}$ wag. \\
\hline & $\nu_{21}$ & $709 \mathrm{vw}$ & $1 /$ & 685 & $-S_{24}(88)$ & $\mathrm{CD}_{2}$ rock. \\
\hline & $\nu_{22}$ & $298 \mathrm{~m}$ & & 303 & $-S_{21}(75)$ & $\mathrm{CCl}$ wag. \\
\hline & $\nu_{23}$ & & & 109 & $-S_{26}(86)$ & Torsion \\
\hline \multirow[t]{9}{*}{$B_{2}$} & $\nu_{24}$ & $2962 \mathrm{w}$ & $\perp$ & 2956 & $-S_{27}(102)$ & $\mathrm{CH}$ str. \\
\hline & $\nu_{25}$ & $2210 \mathrm{w}$ & $\perp$ & 2185 & $-S_{32}(101)$ & $\mathrm{CD}_{2}$ antisym. str. \\
\hline & $\nu_{26}$ & 1252 vs & $\perp$ & 1267 & $-S_{29}(96)$ & $\mathrm{CH}$ bend. \\
\hline & $\nu_{27}$ & & & 1102 & $-S_{33}(65)+S_{35}(61)$ & $\mathrm{CD}_{2}$ wag., $\mathrm{CC}$ str. \\
\hline & $\nu_{28}$ & $955 \mathrm{w}$ & $\perp$ & 947 & $-S_{35}(49)-S_{33}(25)$ & $\mathrm{CC}$ str., $\mathrm{CD}_{2}$ wag. \\
\hline & $\nu_{29}$ & $900 \mathrm{~s}$ & $\perp$ & 912 & $+S_{34}(49)+S_{28}(22)+S_{30}(17)$ & $\mathrm{CD}_{2}$ rock. \\
\hline & $\nu_{30}$ & $565 \mathrm{~s}$ & $\perp$ & 566 & $-S_{28}(81)$ & $\mathrm{CCl}$ str. \\
\hline & $\nu_{31}$ & $390 \mathrm{w}$ & & 412 & $-S_{30}(58)+S_{31}(18)+S_{34}(16)$ & Deform. 1 \\
\hline & $\nu_{32}$ & $275 \mathrm{w}$ & & 280 & $+S_{31}(57)$ & Deform. 2 \\
\hline
\end{tabular}

a Observed data are taken from ref 5 and Figure 4. 
tion of $B_{1}$ ) is left to explain this band. The calculated frequency of $\nu_{23}\left(117 \mathrm{~cm}^{-1}\right)$ is, however, considerably lower than the observed. It is likely that this absorption arises from a mode in which the internal rotation is coupled with a lattice vibration.

According to the selection rule for the $\mathrm{C}_{2 v}$ symmetry, the $A_{2}$ vibrations can be Raman-active while they are infrared-inactive. In the observed Raman spectrum ${ }^{6}$, however, it is rather difficult to pick up the bands which are clearly due to the $A_{2}$ vibrations. On the other hand, the results of depolarization measurements of Raman bands are consistent with the assignments of the bands at $2910,1428,1338,640$ and $364 \mathrm{~cm}^{-1}$ to the $A_{1}$ species.

\section{$P V C-\alpha-d_{1}$}

The first problem is the assignments of the bands at $1360(\perp), 1353(/ /)$, and $1297(\perp) \mathrm{cm}^{-1}$. Krimm, et al. ${ }^{4}$ assigned these bands, respectively, to the $\mathrm{CH}_{2}$ wagging of $\mathrm{B}_{2}$, the $\mathrm{CH}_{2}$ wagging of $B_{1}$, and the $\mathrm{CH}_{2}$ twisting of $A_{1}$. These assignments are supported by our calculation. We note that, just like the case of PVC, the cal-

Table IX. Observed and calculated frequencies (in $\mathrm{cm}^{-1}$ ), potential energy distributions, and band assignments of PVC- $d_{3}$

\begin{tabular}{|c|c|c|c|c|c|c|}
\hline \multicolumn{2}{|c|}{ Mode } & \multicolumn{2}{|c|}{$\begin{array}{c}\text { Obsd frequency } \\
\text { Intensity } \\
\text { Dichroism }^{\mathrm{a}}\end{array}$} & \multirow{2}{*}{$\begin{array}{c}\begin{array}{c}\text { Calcd } \\
\text { frequency }\end{array} \\
2163\end{array}$} & PED & \multirow{2}{*}{$\begin{array}{l}\text { Assignment } \\
\text { CD str. }\end{array}$} \\
\hline$A_{1}$ & $\nu_{1}$ & $2160 \mathrm{~m}$ & $\perp$ & & $-S_{1}(97)$ & \\
\hline & $\nu_{2}$ & $2110 \mathrm{mw}$ & $\perp$ & 2095 & $+S_{6}(96)$ & $\mathrm{CD}_{2}$ sym. str. \\
\hline & $\nu_{3}$ & $1118 \mathrm{~ms}$ & $\perp$ & 1148 & $-S_{10}(54)-S_{7}(22)+S_{8}(21)+S_{5}(19)$ & Skeletal \\
\hline & $\nu_{4}$ & $1040 \mathrm{w}$ & $\perp$ & 1049 & $-S_{7}(55)+S_{3}(22)$ & $\mathrm{CD}_{2}$ scis. \\
\hline & $\nu_{5}$ & & & 982 & $+S_{9}(42)-S_{7}(22)$ & $\mathrm{CD}_{2}$ twist. \\
\hline & $\nu_{6}$ & $865 \mathrm{vw}$ & & 834 & $-S_{3}(67)-S_{9}(26)$ & CD bend. \\
\hline & $\nu_{7}$ & $595 \mathrm{~s}$ & $\perp$ & 589 & $-S_{2}(86)+S_{9}(18)-S_{4}(17)$ & $\mathrm{CCl}$ str. \\
\hline & $\nu_{8}$ & 344 & $\perp$ & 335 & $-S_{4}(58)-S_{5}(16)$ & $\mathrm{CCl}$ bend. \\
\hline & $\nu_{9}$ & & & 53 & $+S_{11}(95)$ & Torsion \\
\hline \multirow[t]{7}{*}{$A_{2}$} & $\nu_{10}$ & & & 2098 & $-S_{14}(101)$ & $\mathrm{CD}_{2}$ sym. str. \\
\hline & $\nu_{11}$ & & & 1118 & $-S_{18}(72)-S_{15}(25)-S_{12}(24)$ & $\mathrm{CC}$ str. \\
\hline & $\nu_{12}$ & & & 1064 & $-S_{15}(61)+S_{12}(29)$ & $\mathrm{CD}_{2}$ scis. \\
\hline & $\nu_{13}$ & & & 900 & $-S_{18}(35)+S_{12}(20)$ & CC str., CD wag. \\
\hline & $\nu_{14}$ & & & 806 & $-S_{17}(84)-S_{12}(19)$ & $\mathrm{CD}_{2}$ twist. \\
\hline & $\nu_{15}$ & & & 498 & $+S_{16}(59)+S_{13}(29)$ & CCC bend. \\
\hline & $\nu_{16}$ & & & 127 & $-S_{13}(67)+S_{16}(34)$ & CCl wag. \\
\hline \multirow[t]{7}{*}{$B_{1}$} & $\nu_{17}$ & & & 2184 & $+S_{22}(102)$ & $\mathrm{CD}_{2}$ antisym. str. \\
\hline & $\nu_{18}$ & $1256 \mathrm{mw}$ & $/ /$ & 1252 & $+S_{25}(85)-S_{23}(27)+S_{20}(23)$ & CC str. \\
\hline & $\nu_{19}$ & $940 \mathrm{~m}$ & $/ /$ & 951 & $-S_{20}(60)-S_{23}(24)$ & $\mathrm{CD}$ wag. \\
\hline & $\nu_{20}$ & & & 863 & $+S_{23}(56)+S_{25}(19)$ & $\mathrm{CD}_{2}$ wag. \\
\hline & $\nu_{21}$ & $670 \mathrm{mw}$ & & 656 & $-S_{24}(77)-S_{20}(19)$ & $\mathrm{CD}_{2}$ rock. \\
\hline & $\nu_{22}$ & 300 & $/ /$ & 303 & $-S_{21}(75)$ & $\mathrm{CCl}$ wag. \\
\hline & $\nu_{23}$ & & & 107 & $-S_{26}(85)$ & Torsion \\
\hline \multirow[t]{9}{*}{$B_{2}$} & $\nu_{24}$ & $2230 \mathrm{~m}$ & $\perp$ & 2186 & $+S_{32}(96)$ & $\mathrm{CD}_{2}$ antisym. str. \\
\hline & $\nu_{25}$ & $2160 \mathrm{mw}$ & $\perp$ & 2158 & $-S_{27}(98)$ & CD str. \\
\hline & $\nu_{26}$ & & & 1102 & $+S_{33}(64)-S_{35}(63)$ & $\mathrm{CD}_{2}$ wag., $\mathrm{CC}$ str. \\
\hline & $\nu_{27}$ & $1010 \mathrm{~ms}$ & $\perp$ & 1040 & $+S_{29}(54)-S_{34}(22)-S_{28}(17)$ & $\mathrm{CD}$ bend. \\
\hline & $\nu_{28}$ & & & 934 & $+S_{35}(39)+S_{33}(21)$ & CC str. \\
\hline & $\nu_{29}$ & $792 \mathrm{~ms}$ & $\perp$ & 802 & $+S_{29}(45)+S_{34}(22)$ & CD bend. \\
\hline & $\nu_{30}$ & $560 \mathrm{~s}$ & $\perp$ & 565 & $-S_{28}(82)$ & $\mathrm{CCl}$ str. \\
\hline & $\nu_{31}$ & 390 & $\perp$ & 405 & $-S_{30}(59)+S_{31}(17)+S_{34}(16)$ & Deform. 1 \\
\hline & $\nu_{32}$ & 275 & & 277 & $+S_{31}(59)$ & Deform. 2 \\
\hline
\end{tabular}

a Observed data are taken from ref 4 and 8 . 
culated frequency of the $\mathrm{CH}_{2}$-wagging mode of $B_{2}\left(1308 \mathrm{~cm}^{-1}\right)$ is considerably lower than the observed $\left(1360 \mathrm{~cm}^{-1}\right)$. The strong absorption at $1080 \mathrm{~cm}^{-1}$ may be assigned to $\nu_{27}$, in which the $\mathrm{CH}_{2}$-rocking and $\mathrm{CD}$-bending coordinates are coupled.

It seems reasonable from the results of calculation to associate the bands at 1160,1110 , and $1020 \mathrm{~cm}^{-1}$ to $\nu_{19}\left(B_{1}\right), \nu_{5}\left(A_{1}\right)$, and $\nu_{28}\left(B_{2}\right)$, respectively, though the dichroism of the former two bands is ambiguous. The parallel bands at 1000 and $769 \mathrm{~cm}^{-1}$ may be assigned to $\nu_{20}$ and $\nu_{21}$, both of which have the components of $\mathrm{CH}_{2}$ rocking and $\mathrm{CD}$-wagging modes.

The CCl-stretching modes are shifted to slightly lower frequencies by $\alpha$-deuteration. The crystalline bands at 625 and $598 \mathrm{~cm}^{-1}$ are assigned to $\nu_{7}\left(A_{1}\right)$ and $\nu_{30}\left(B_{2}\right)$, respectively. The $358 \mathrm{~cm}^{-1}$ band may be assigned to $\nu_{8}\left(\mathrm{CCl}\right.$-bending of $\left.A_{1}\right)$. The $345 \mathrm{~cm}^{-1}$ band is assigned to $\nu_{22}(\mathrm{CCl}$ wagging of $B_{1}$ ) from its parallel dichroism. The $297 \mathrm{~cm}^{-1}$ band is undoubtedly due to $\nu_{32}(\mathrm{CCl}-$ bending mode of $B_{2}$ ).

Table X. Observed and calculated frequencies (in $\mathrm{cm}^{-1}$ ), potential energy distributions, and band assignments of PVC- $\beta-d_{1}$

\begin{tabular}{|c|c|c|c|c|c|c|}
\hline \multirow{2}{*}{\multicolumn{2}{|c|}{$\begin{array}{l}\text { Mode } \\
A^{\prime} \quad \nu_{1}\end{array}$}} & \multicolumn{2}{|c|}{$\begin{array}{l}\text { Obsd frequency } \\
\text { Intensity } \\
\text { Dichroism }^{\mathrm{a}}\end{array}$} & \multirow{2}{*}{$\begin{array}{c}\begin{array}{c}\text { Calcd } \\
\text { frequency }\end{array} \\
2959\end{array}$} & \multirow[t]{2}{*}{ PED } & \multirow{2}{*}{$\begin{array}{l}\text { Assignment } \\
\mathrm{CH}(\alpha) \text { str. }\end{array}$} \\
\hline & & $2980 \mathrm{~m}$ & $\perp$ & & & \\
\hline & $\nu_{2}$ & $2920 \mathrm{~ms}$ & $\perp$ & 2922 & $-S_{22}(51)+S_{6}(43)$ & $\mathrm{CH}(\beta)$ str. \\
\hline & $\nu_{3}$ & $2170 \mathrm{w}$ & $\perp$ & 2141 & $-S_{6}(55)-S_{22}(46)$ & CD str. \\
\hline & $\nu_{4}$ & $1372 \mathrm{mw}$ & $\perp$ & 1391 & $+S_{20}(59)+S_{25}(26)-S_{23}(19)$ & $\mathrm{CH}(\alpha)$ wag. \\
\hline & $\nu_{5}$ & 1292 vs & $\perp$ & 1309 & $-S_{7}(50)+S_{3}(25)$ & $\mathrm{CH}(\beta)$ bend., $\mathrm{CH}(\alpha)$ bend. \\
\hline & $\nu_{6}$ & $1263 \mathrm{vs}$ & $\perp$ & 1269 & $+S_{7}(50)+S_{3}(25)$ & $\mathrm{CH}(\beta)$ bend., $\mathrm{CH}(\alpha)$ bend. \\
\hline & $\nu_{7}$ & $1210 \mathrm{mw}$ & // & 1195 & $-S_{23}(37)+S_{3}(36)-S_{20}(18)$ & $\mathrm{CH}(\beta)$ wag. \\
\hline & $\nu_{8}$ & $1140 \mathrm{mw}$ & $/ 1$ & 1127 & $+S_{10}(44)-S_{25}(20)-S_{8}(17)$ & Skeletal \\
\hline & $\nu_{9}$ & $1090 \mathrm{mw}$ & $\perp$ & 1095 & $-S_{25}(43)+S_{9}(16)$ & CC str. \\
\hline & $\nu_{10}$ & $872 \mathrm{~m}$ & & 904 & $+S_{23}(38)+S_{9}(29)$ & CD wag. \\
\hline & $\nu_{11}$ & $747 \mathrm{mw}$ & // & 733 & $-S_{24}(85)$ & CHD rock. \\
\hline & $\nu_{12}$ & $622 \mathrm{~s}$ & $\perp$ & 613 & $+S_{2}(87)+S_{4}(20)$ & $\mathrm{CCl}$ str. \\
\hline & $\nu_{13}$ & 353 & $\perp$ & 346 & $+S_{4}(53)$ & $\mathrm{CCl}$ bend. \\
\hline & $\nu_{14}$ & 318 & $/ /$ & 321 & $-S_{21}(71)$ & $\mathrm{CCl}$ wag. \\
\hline & $\nu_{15}$ & & & 113 & $+S_{26}(83)$ & Torsion \\
\hline & $\nu_{16}$ & & & 54 & $-S_{11}(95)$ & Torsion \\
\hline \multirow{16}{*}{$A^{\prime \prime}$} & $\nu_{17}$ & $2980 \mathrm{~m}$ & $\perp$ & 2957 & $-S_{27}(98)$ & $\mathrm{CH}(\alpha)$ str. \\
\hline & $\nu_{18}$ & $2920 \mathrm{~ms}$ & $\perp$ & 2923 & $+S_{32}(53)-S_{14}(45)$ & $\mathrm{CH}(\beta)$ str. \\
\hline & $\nu_{19}$ & $2170 \mathrm{w}$ & $\perp$ & 2140 & $+S_{14}(55)+S_{32}(46)$ & CD str. \\
\hline & $\nu_{20}$ & $1340 \mathrm{mw}$ & $\perp$ & 1344 & $+S_{12}(68)$ & $\mathrm{CH}(\alpha)$ wag. \\
\hline & $\nu_{21}$ & 1292 vs & $\perp$ & 1304 & $+S_{15}(63)-S_{29}(24)$ & $\mathrm{CH}(\beta)$ bend., $\mathrm{CH}(\alpha)$ bend. \\
\hline & $\nu_{22}$ & $1240 \mathrm{vs}$ & $\perp$ & 1260 & $+S_{29}(63)+S_{15}(26)$ & $\mathrm{CH}(\alpha)$ bend., $\mathrm{CH}(\beta)$ bend. \\
\hline & $\nu_{23}$ & & & 1237 & $+S_{33}(57)-S_{12}(22)$ & $\mathrm{CH}(\beta)$ wag. \\
\hline & $\nu_{24}$ & & & 1032 & $-S_{35}(74)+S_{18}(21)$ & CC str. \\
\hline & $\nu_{25}$ & & & 1020 & $+S_{18}(71)+S_{35}(18)$ & CC str. \\
\hline & $\nu_{26}$ & $904 \mathrm{~ms}$ & $\perp$ & 929 & $+S_{34}(47)+S_{30}(20)$ & CHD rock. \\
\hline & $\nu_{27}$ & $872 \mathrm{~m}$ & & 888 & $-S_{17}(57)-S_{33}(15)$ & CD wag. \\
\hline & $\nu_{28}$ & $580 \mathrm{~s}$ & $\perp$ & 589 & $-S_{28}(81)-S_{31}(17)$ & $\mathrm{CCl}$ str. \\
\hline & $\nu_{29}$ & & & 538 & $-S_{16}(61)-S_{13}(28)$ & CCC bend. \\
\hline & $\nu_{30}$ & 407 & & 436 & $+S_{30}(63)$ & Deform. 1 \\
\hline & $\nu_{31}$ & & & 294 & $-S_{31}(60)$ & Deform. 2 \\
\hline & $\nu_{32}$ & & & 127 & $+S_{13}(67)$ & $\mathrm{CCl}$ wag. \\
\hline
\end{tabular}

a Observed data are taken from ref 4 and 8. 


\section{Tasumi and T. Shimanouchi}

\section{$P V C-\beta, \beta-d_{2}$}

The parallel bands at $1325,1167,885$, and $709 \mathrm{~cm}^{-1}$ may be explained by $\nu_{18}, \nu_{19}, \nu_{20}$, and $\nu_{21}$.

The strong band at $1252 \mathrm{~cm}^{-1}$ is due to the two CH-bending modes, $\nu_{3}\left(A_{1}\right)$ and $\nu_{26}\left(B_{2}\right)$. In this polymer the $\mathrm{CH}$ bending mode is free from the coupling with other modes. As a result the calculated frequencies of $\nu_{3}$ and $\nu_{26}$ are not much different. The band at $1105 \mathrm{~cm}^{-1}$ may be assigned to $\nu_{4}$ (skeletal mode of $A_{1}$ ). The 1020 $\mathrm{cm}^{-1}$ band is certainly due to $\nu_{5}\left(\mathrm{CD}_{2}\right.$-scissor mode of $A_{1}$ ). The strong band at $900 \mathrm{~cm}^{-1}$ arises from $\nu_{29}\left(C_{2}\right.$-rocking mode of $\left.B_{2}\right)$. The corresponding band is found at $960 \mathrm{~cm}^{-1}$ in the spectrum of PVC. There is no simple corresponding band in the spectrum of PVC- $\alpha-d_{1}$ because of the coupling between $\mathrm{CH}_{2}$-rocking and CD-bending modes. This provides a good example of the difficulties in predicting the frequencies of deuterated compounds without normal-coordinate treatments.

The $\mathrm{CCl}$ stretching frequencies are shifted down much more by $\beta$-deuteration $\left(\nu\left(A_{1}\right)\right.$ is shifted

Table XI. Observed and calculated frequencies (in $\mathrm{cm}^{-1}$ ), potential energy distributions, and band assignments of PVC- $\alpha, \beta-d_{2}$

\begin{tabular}{|c|c|c|c|c|c|c|}
\hline \multicolumn{2}{|c|}{ Mode } & \multicolumn{2}{|c|}{$\begin{array}{l}\text { Obsd frequency } \\
\text { Intensity } \\
\text { Dichroism }^{\mathrm{a}}\end{array}$} & \multirow{2}{*}{$\begin{array}{c}\begin{array}{c}\text { Calcd } \\
\text { frequency }\end{array} \\
2924\end{array}$} & \multirow[b]{2}{*}{$+S_{22}(55)+S_{6}(46)$} & \multirow{2}{*}{$\begin{array}{l}\text { Assignment } \\
\text { CH str. }\end{array}$} \\
\hline$A^{\prime}$ & $\nu_{1}$ & $2920 \mathrm{~ms}$ & $\perp$ & & & \\
\hline & $\nu_{2}$ & $2208 \mathrm{w}$ & $\perp$ & 2165 & $-S_{1}(83)$ & $\mathrm{CD}(\alpha)$ str. \\
\hline & $\nu_{3}$ & $2180 \mathrm{w}$ & $\perp$ & 2135 & $-S_{6}(46)+S_{22}(37)-S_{1}(19)$ & $\mathrm{CD}(\beta)$ str. \\
\hline & $\nu_{4}$ & $1330 \mathrm{~m}$ & $\perp$ & 1312 & $-S_{23}(51)+S_{25}(40)-S_{9}(16)$ & CHD wag., CC str. \\
\hline & $\nu_{5}$ & $1282 \mathrm{~s}$ & $\perp$ & 1291 & $+S_{7}(87)$ & CHD scis. \\
\hline & $\nu_{6}$ & $1185 \mathrm{mw}$ & $\perp$ & 1181 & $-S_{25}(39)-S_{9}(34)$ & CC str., CHD twist. \\
\hline & $\nu_{7}$ & $1115 \mathrm{vw}$ & & 1123 & $-S_{10}(53)+S_{8}(21)+S_{5}(17)$ & Skeletal \\
\hline & $\nu_{8}$ & $962 \mathrm{mw}$ & $\perp$ & 973 & $-S_{20}(39)-S_{23}(28)$ & $\mathrm{CD}(\alpha)$ wag., $\mathrm{CHD}$ wag. \\
\hline & $\nu_{9}$ & $938 \mathrm{mw}$ & $\perp$ & 917 & $-S_{25}(21)-S_{3}(18)$ & $\mathrm{CC}$ str., $\mathrm{CD}(\alpha)$ bend. \\
\hline & $\nu_{10}$ & 816 vw & & 843 & $-S_{3}(63)-S_{9}(22)$ & $\mathrm{CD}(\alpha)$ bend. \\
\hline & $\nu_{11}$ & $705 \mathrm{mw}$ & $/ /$ & 695 & $-S_{24}(69)-S_{20}(25)$ & CHD rock. \\
\hline & $\nu_{12}$ & $615 \mathrm{~s}$ & $\perp$ & 607 & $-S_{2}(87)-S_{4}(19)$ & $\mathrm{CCl}$ str. \\
\hline & $\nu_{13}$ & 352 & & 342 & $+S_{4}(53)$ & $\mathrm{CCl}$ bend. \\
\hline & $\nu_{14}$ & 316 & & 320 & $-S_{21}(69)$ & $\mathrm{CCl}$ wag. \\
\hline & $\nu_{15}$ & & & 111 & $+S_{26}(83)-S_{20}(39)$ & Torsion \\
\hline & $\nu_{16}$ & & & 53 & $+S_{11}(95)$ & Torsion \\
\hline \multirow[t]{16}{*}{$A^{\prime \prime}$} & $\nu_{17}$ & $2920 \mathrm{~ms}$ & $\perp$ & 2924 & $+S_{32}(55)+S_{14}(46)$ & $\mathrm{CH}$ str. \\
\hline & $\nu_{18}$ & $2208 \mathrm{w}$ & $\perp$ & 2160 & $+S_{27}(99)$ & $\mathrm{CD}(\alpha)$ str. \\
\hline & $\nu_{19}$ & $2180 \mathrm{w}$ & $\perp$ & 2139 & $-S_{14}(53)+S_{32}(45)$ & $\mathrm{CD}(\beta)$ str. \\
\hline & $\nu_{20}$ & $1310 \mathrm{vw}$ & & 1294 & $-S_{15}(90)$ & CHD scis. \\
\hline & $\nu_{21}$ & $1238 \mathrm{w}$ & $\perp$ & 1270 & $-S_{33}(70)-S_{17}(25)$ & $\mathrm{CH}(\beta)$ wag. \\
\hline & $\nu_{22}$ & $1115 \mathrm{vw}$ & & 1105 & $+S_{18}(56)+S_{12}(38)$ & CC str., CD wag. \\
\hline & $\nu_{23}$ & $1025 \mathrm{~s}$ & $\perp$ & 1054 & $+S_{29}(42)+S_{35}(34)-S_{34}(16)$ & CD bend., CC str. \\
\hline & $\nu_{24}$ & $1058 \mathrm{w}$ & & 1023 & $-S_{35}(48)-S_{17}(16)$ & CC str. \\
\hline & $\nu_{25}$ & $918 \mathrm{vw}$ & & 919 & $+S_{18}(28)-S_{12}(18)$ & CC str., CD wag. \\
\hline & $\nu_{26}$ & $880 \mathrm{w}$ & $\perp$ & 879 & $-S_{17}(40)-S_{12}(24)$ & CHD twist. \\
\hline & $\nu_{27}$ & $802 \mathrm{~m}$ & $\perp$ & 807 & $+S_{29}(42)+S_{34}(18)$ & $\mathrm{CD}(\mu)$ bend., $\mathrm{CHD}$ rock. \\
\hline & $\nu_{28}$ & $580 \mathrm{~s}$ & $\perp$ & 585 & $+S_{28}(85)+S_{31}(17)$ & $\mathrm{CCl}$ str. \\
\hline & $\nu_{29}$ & & & 507 & $-S_{16}(58)-S_{13}(28)$ & CCC bend. \\
\hline & $\nu_{30}$ & 403 & & 429 & $-S_{30}(64)$ & Deform. 1 \\
\hline & $\nu_{31}$ & 288 & & 290 & $-S_{31}(62)$ & Deform. 2 \\
\hline & $\nu_{32}$ & & & 127 & $-S_{13}(67)+S_{16}(34)$ & $\mathrm{CCl}$ wag., $\mathrm{CCC}$ bend. \\
\hline
\end{tabular}

a Observed data are taken from ref 4 and 8 . 
from 640 to $599 \mathrm{~cm}^{-1}$ and $\nu\left(B_{2}\right)$ from 604 to $565 \mathrm{~cm}^{-1}$ ) than by $\alpha$-deuteration $\left(\nu\left(A_{1}\right)\right.$ from 640 to $625 \mathrm{~cm}^{-1}, \nu\left(B_{2}\right)$ from 604 to $\left.598 \mathrm{~cm}^{-1}\right)$. The calculation follows satisfactorily these experimental findings.

Figure 4 shows the low-frequency spectrum of this polymer, which we measured for the sample provided by Enomoto. The bands at $390,348,298$, and $275 \mathrm{~cm}^{-1}$ may be assigned to $\nu_{31}, \nu_{8}, \nu_{22}$, and $\nu_{32}$, respectively. It is noted that $\nu_{22}$ is greatly affected by the $\beta$-deuteration. Three bands are found in the region below 200 $\mathrm{cm}^{-1}$. Their origins are ambiguous, however. Probably the band at $172 \mathrm{~cm}^{-1}$ is analogous to the $187-\mathrm{cm}^{-1}$ band of PVC.

\section{$P V C-d_{3}$}

Assignments of bands having major intensities may be made without much difficulty in reference to the results of our calculations. We have changed some of our former assignments ${ }^{1}$. For instance, the strong band at $1010 \mathrm{~cm}^{-1}$ is now assigned to $\nu_{27}$ (a $B_{2}$ mode in which the CD-bending, $\mathrm{CD}_{2}$-rocking, and CCl-stretching coordinates are mixed) rather than to $\nu_{4}$ (an $A_{1}$ mode which is mainly composed of the $\mathrm{CD}_{2^{-}}$ scissor and CD-bending coordinates). To the latter the shoulder band at $1040 \mathrm{~cm}^{-1}$ is assigned. It seems more reasonable to associate a mode having a large CD-bending $\left(B_{2}\right)$ component to a band with greater intensity, since in the PVC spectrum $\nu_{27}$ (almost pure CH-bending mode of $\left.B_{2}\right)$ has the strongest intensity.

\section{$P V C-\beta-d_{1}$ and $P V C-\alpha, \beta-d_{2}$}

Assignments are a little more difficult for PVC- $\beta-d_{1}$ and PVC- $\alpha, \beta-d_{2}$, because the symmetry of these polymers is not higher than $\mathrm{C}_{s}$. For the $\mathrm{C}_{2 v}$ structure we could pick up the $B_{1}$ bands easily as they should show parallel dichroism. For the $\mathrm{C}_{s}$ structure the transition moments of the $A^{\prime}$ modes are limited in the skeletal plane, whereas those of the $A^{\prime \prime}$ modes are perpendicular to the plane. The problem is that there is no further prediction regarding the direction of the $\boldsymbol{A}^{\prime}$ transition moments. Under such circumstances it is reasonable to expect that, if an $A^{\prime}$ normal coordinates is made up almost solely of the $B_{1}$ symmetry coordinates of $\mathrm{C}_{2 v}$, the band due to the normal mode would show parallel dichroism. For example, $\nu_{11}\left(\nu_{\text {calc }}=733 \mathrm{~cm}^{-1}\right)$ and $\nu_{14}\left(\nu_{\text {calc }}=321 \mathrm{~cm}^{-1}\right)$ of PVC- $\beta-d_{1}$ are mostly composed of the $B_{1}$ coordinates. Parallel bands at 747 and $318 \mathrm{~cm}^{-1}$ may, therefore, be assigned to them. It appears, however, that there is no simple way of predicting the direction of the transition moment when considerable coupling. of the $A_{1}$ and $B_{1}$ modes takes place in a normal mode.

In the spectrum of PVC- $\alpha, \beta-d_{2}$ no definitely parallel band has been obsereed in the $\mathrm{NaCl}$ region except for the $705-\mathrm{cm}^{-1}$ band. This fact suggests that the coupling of the $A_{1}$ and $B_{1}$ coordinates in the $A^{\prime}$ species of this polymer has a great effect on the direction of the transition moment.

In conclusion we may say that it was possible to assign most of the main bands of deuterated polymers reasonably well with the aid of the calculations. This increases the reliability of band assignments of nondeuterated polymer.

Acknowledgment. We are greatful to Dr. S. Enomoto of Kureha Chemical Industry Co. for giving us the sample of PVC- $\beta, \beta-d_{2}$.

\section{REFERENCES}

1. T. Shimanouchi and M. Tasumi, Bull. Chem. Soc. Japan, 34, 359 (1961).

2. (a) M. Tasumi, T. Shimanouchi, and T. Miyazawa, J. Mol. Spectrosc., 9, 261 (1962); 11, 422. (1963); (b) M. Tasumi and T. Shimanouchi, $J$. Chem. Phys., 43, 1245 (1965).

3. M. Tasumi and T. Shimanouchi, Spectrochim. Acta, 17, 731 (1961).

4. S. Krimm, V. L. Folt, J. J. Shipman, and A. R. Berens, J. Polym. Sci., Part A, 1, 2621 (1963).

5. S. Enomoto, M. Asahina, and S. Satoh, $J$. Polym. Sci., Part A-1, 41373 (1966).

6. J. L. Koenig and D. Druesedow, J. Polym. Sci., Part A-2, 7, 1075 (1969).

7. T. Shimanouchi, J. Chem. Phys., 17, 245 (1949).

8. C. G. Opaskar, Ph. D. Thesis, University of Michigan, Ann Arbor, Michigan, 1966. 